\title{
CORRECTION
}

\section{Correction: Prefrontal cortex and depression}

Diego A. Pizzagalli (iD) and Angela C. Roberts (D)

(c) The Author(s), under exclusive licence to American College of Neuropsychopharmacology 2021

Neuropsychopharmacology (2022) 47:609; https://doi.org/10.1038/s41386-021-01160-w

Correction to: Neuropsychopharmacology https://doi.org/10.1038/ s41386-021-01101-7, published online 02 August 2021
The wrong Supplementary File was originally published with this article; it has now been deleted.

The original article has been corrected. 